\title{
Progress towards the UN Commission on Life Saving Commodities recommendations after five years: a longitudinal assessment
}

\author{
Bennett Nemser', Diana Sera ${ }^{2}$, Nora Springstubb ${ }^{3}$, Paul Pronyk ${ }^{4}$, Howard S Friedman ${ }^{5}$, Theopista Kabuteni ${ }^{6}$, Asia \\ Hussein', Kyaw Aung, Felister Bwana ${ }^{8}$, Nicholas Addofoh', Miriam Musa ${ }^{10}$, Pascal Bijleveld ${ }^{11}$, Blerta Maliqi ${ }^{12}$ \\ 1 University of the Western Cape, Cape Town, South Africa, ${ }^{2}$ UNICEF, New York, United States, ${ }^{3}$ Public Health Institute, Oakland, CA, United States, 4 \\ UNICEF, Jakarta, Indonesia, ${ }^{5}$ UNFPA, New York, United States, ${ }^{6}$ World Health Organization, Kigali, Rwanda, 7 UNICEF, Dar Es Salaam, Tanzania, 8 \\ UNFPA, Dar Es Salaam, Tanzania, ${ }^{9}$ Infrastructure for Sustainable Development, New York, New York, United States, 10 Plan International, Toronto, \\ Canada, ${ }^{11}$ GAVI, Geneva, Switzerland, ${ }^{12}$ World Health Organization, Geneva, Switzerland \\ Keywords: essential medicines, life-saving commodities, rmnch \\ https://doi.org/10.29392/001c.12745
}

\section{Journal of Global Health Reports}

Vol. 4, 2020

\begin{abstract}
Background
In 2012, the UN Commission on Life Saving Commodities (UNCoLSC) articulated a series of recommendations to expand access to 13 life-saving reproductive, maternal, newborn and child health (RMNCH) commodities with the greatest potential to reduce preventable deaths. We conducted a five-year longitudinal assessment of progress towards achieving these recommendations among countries in sub-Saharan Africa and Southeast Asia.
\end{abstract}

\section{Methods}

Between 2013 and 2017, national reviews were undertaken at two time points among 14 countries with a high burden of preventable maternal-child deaths who were receiving support from a multi-UN agency RMNCH technical support and financing mechanism. Data were drawn from national health documentation (e.g. strategic plans, policies, guidelines); logistics management information systems; national household and health facility surveys; and interviews with governments and development partners.

\section{Results}

Over time, the percent of health facilities with stock availability showed a statistically significant increase of five percentage points from $69 \%$ to $74 \%$ (median). Recent training at health facility also displayed a significant increase of eight percentage points from $38 \%$ to $46 \%$ (median). National RMNCH coordination mechanisms, treatment guidelines, and national training curricula and job-aids were near fully redressed. However, countries continue to face persistent supply chain challenges including national stock-outs, tracking commodities throughout the supply chain, and strengthening medicine control laboratories.

\section{Conclusions}

While substantial progress has been made in improving access to life-saving commodities, including stock availability and workforce training at health facilities, additional efforts are required to improve regulatory efficiency, enhance commodity quality and safety, and reduce supply chain fragmentation.

\section{INTRODUCTION}

Over the past two decades, substantial declines in maternal, newborn and child mortality have been observed among least developed countries. ${ }^{1-3}$ However, preventable deaths take place far too commonly ${ }^{4}$ with maternal deaths underpinned by pregnancy-induced hypertension, post-partum bleeding and infection ${ }^{5}$; newborn deaths linked to preterm birth complications, intrapartum events, and infection (sepsis / meningitis) ${ }^{6}$; and child mortality led by pneumonia and diarrhea incidence. ${ }^{1,6}$ Despite improved access to healthcare, ${ }^{5}$ the quality of these services often remains substandard. ${ }^{7-10}$

Systems to ensure availability and access to safe, effective and affordable reproductive, maternal, newborn and child health (RMNCH) commodities can make major inroads in the prevention and management of the most common causes of mortality. ${ }^{5}$ The UN Commission on Life-saving Commodities for Women and Children (UNCoLSC) was established to articulate key bottlenecks and define strategies to address them. In its report from September 2012, ${ }^{11}$ the Commission prioritized 13 low-cost and high-impact commodities across the RMNCH spectrum (Figure 1) that if im- 


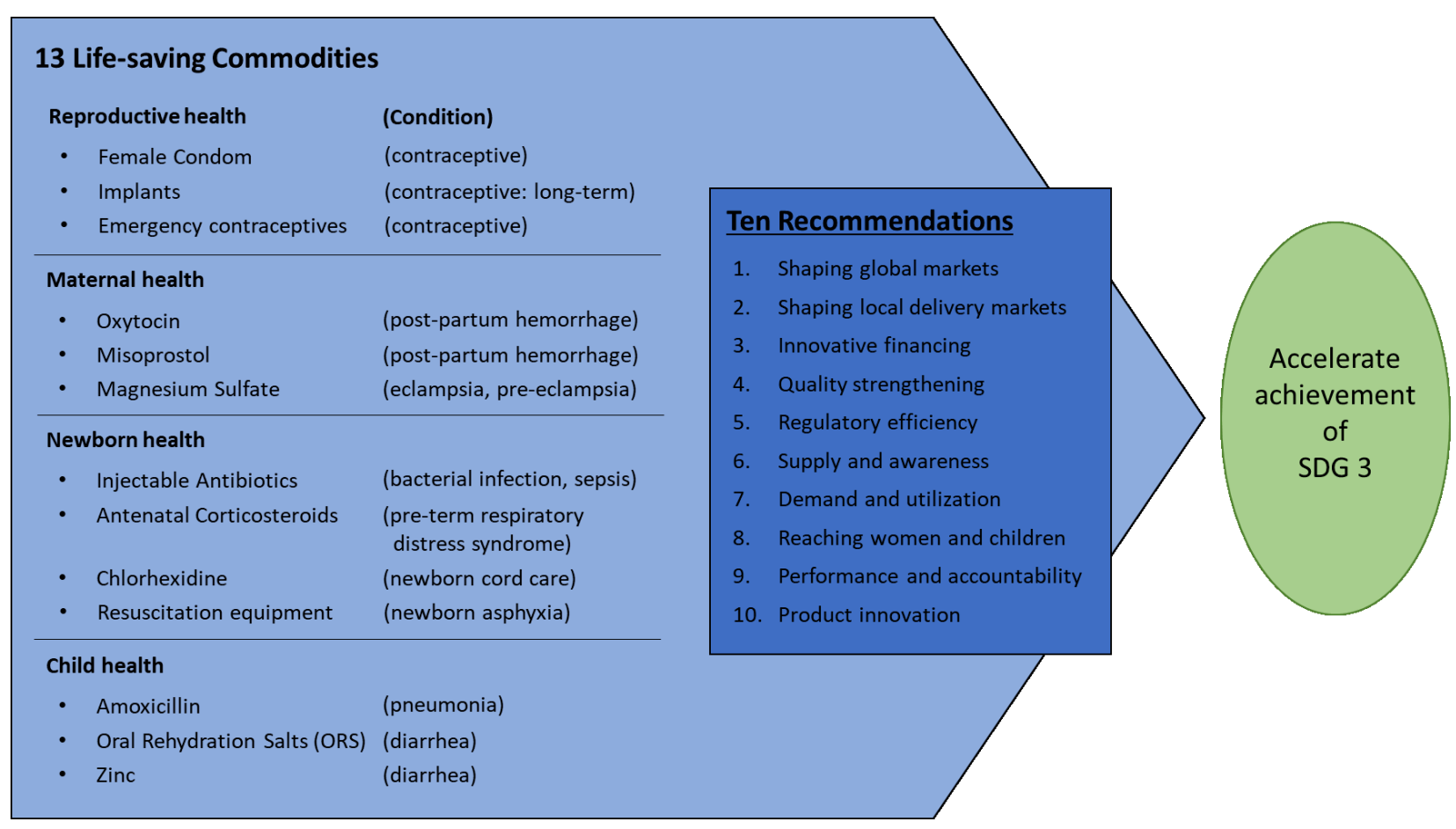

Figure 1: UNCoLSC Recommendations to improve access to 13 Life-Saving Commodities (and primary condition)

plemented at-scale could make a substantial impact in reducing preventable deaths. The UNCoLSC also outlined a set of recommendations for addressing wider health system challenges that required concurrent attention - from procurement and regulatory systems and supply chains, to upto-date health worker training materials (Figure 1). While limited in number, the 13 prioritized commodities were intended to act as tracers to provide a high-impact focus in the face of multiple competing priorities.

To take forward the UNCoLSC agenda, a multi-UN agency technical support and financing mechanism was established to accelerate progress towards maternal and child mortality goals among countries where progress was offtrack. Three main strategies were implemented. ${ }^{12}$ First, a country engagement process was undertaken to generate RMNCH acceleration plans. This included a systematic assessment of RMNCH commodity-related bottlenecks, an identification of prioritized interventions, an assessment of technical and financial contributions from development partners (i.e. resource mapping), and an articulation of critical resource gaps. This country engagement process was led by the government, shaped by International Health Partnership principles, ${ }^{13}$ and informed by global and country-level partners. Second, catalytic financial resources were made available from a multi-UN agency financing mechanism (RMNCH Fund) to support RMNCH acceleration plans. Third, a network of technical resource teams provided additional support to address global barriers and facilitate country implementation.

The aim of this paper is to examine country-level progress against the UNCoLSC recommendations over a five-year period. The specific objectives are to profile availability and access to the 13 commodities and the status of key health systems enablers among high-burden countries; to document specific areas of progress and remaining bottlenecks; and to generate learning to inform the Sustainable Development Goal framework and Universal Health Coverage (UHC) agendas.

\section{METHODS}

To assess the baseline status and progress towards the UNCoLSC recommendations, an RMNCH situation analysis was conducted in countries receiving support from the RMNCH Fund. This analysis included a synthesis of existing data sources including governmental and partner documents (e.g. national strategic plans, essential medicines lists, treatment guidelines, regulatory and policy briefs, commodity registers, training curricula), and aggregated quantitative measures from various sources (e.g. health facility assessments, health and logistics management information systems). These data sources were complemented by semistructured interviews with government officials, programme managers, regulatory and supply chain agencies and in-country partners. The situation analysis and performance indicators (Tables 1 and 2) were designed in consultation with the UNCoLSC technical resource teams (TRTs), a network of approximately 450 experts across 85 organizations, as well as the UNCoLSC Monitoring and Evaluation Advisory Group. ${ }^{12}$

Within each country, the situation analysis was typically completed over a 2-4 weeks by a trained facilitator, who collaborated with local ministries, UN country teams and incountry partners. These efforts were supported by a multi-UN agency Strategy and Coordination Team (SCT), which facilitated engagement with in-country partners, trained enumerators, coordinated content review, and performed standardized analysis to provide consistency of results 
across countries and over time. The SCT conducted quality assurance on each country assessment and reviewed the results, data sources, and list of experts interviewed with country teams to ensure accuracy and completeness. While national ministries had discretion over the timing of data collection, this study includes countries where a baseline round of data collection was conducted within one year of program initiation (2014-2015; see Online Supplementary Document Table A) and where a repeat round took place during 2016 or 2017. Results from country assessments were entered into a relational database (MS Access, Microsoft Inc, Seattle, WA, USA), processed using R software (R version 3.2.0, Vienna, Austria), and uploaded to a web-based platform and documented in summary reports for review by country teams. Detailed methods and initial results were previously published. ${ }^{12}$ All statistical analyses with estimates were conducted in STATA software version 14 (College Station, TX, USA).

\section{QUANTITATIVE INDICATORS}

Quantitative indicators derived from nationally-representative population- and facility-based surveys are defined in Table 1. To assess change-over-time, indicators from the most recent available survey (i.e. endline) were compared to an earlier data collection (defined as since 2010 and prior to RMNCH Fund initial implementation within each respective country). Selection of data pairs (baseline and endline data points) prioritized comparable indicator generation methods and recency of collection. If data prior to RMNCH Fund implementation was unavailable, then the earliest data source after implementation was used to illustrate trends. In order to identify all available population- and facility-based survey data sources, the SCT consulted with country teams, global UN agencies and development partners to ensure dataset completeness. Results from population- and facility-based surveys were included if available by June 2019 . For quantitative indicators, non-parametric paired t-tests were used, due to skewness, to assess statistical significance between baseline and endline distributions.

\section{CATEGORICAL INDICATORS}

A range of categorical indicators for assessing wellknown ${ }^{14,15}$ in-country health system and commodity-specific bottlenecks were defined through consultation with a global network of technical experts ${ }^{12}$ (Table 2). A standardized assessment criteria was developed (see Online Supplementary Document Table $\mathrm{H}$ ) and dichotomous conditions to meet the minimum performance threshold were defined in Table 2 to ensure comparability across countries. These categorical indicators were collected during the country-specific situation analysis with baseline and endline time periods listed in Online Supplementary Document Table A. Indicators related to health systems are reported once per country, while commodity-specific indicators are reported once per commodity per country (i.e. up to 13 times per country). To evaluate statistical significant for categorical indicators, paired t-tests were used between average baseline and endline values.

\section{RESULTS}

Between January 2013 to December 2017, 14 countries in sub-Saharan Africa and Southeast Asia underwent two assessment rounds including Bangladesh, Benin, Burkina Faso, Cameroon, Democratic Republic of the Congo (DRC), Ethiopia, Malawi, Mali, Nigeria, Pakistan, Senegal, Sierra Leone, Tanzania and Zambia (see Online Supplementary Document Table A for complete list and timeline of data sources).

\section{COMMODITY AVAILABILITY AND LOGISTICS MANAGEMENT}

Analysis of stock availability - defined as commodity physically available at health facility at time of assessment - is profiled in Table 1 and disaggregated by commodity in Figure 2. Collectively, there was a statistically significant increase of five percentage points in stock availability of lifesaving commodities over the observation period (69\% to $74 \%, P=.001$, Table 1 ). Commodities with the largest improvement included Magnesium Sulfate (24 percentage point increase), Misoprostol (+25 pp) and injectable antibiotics for newborns (+11 pp). Notably, Misoprostol and Magnesium Sulfate had among the lowest baseline availability and thus greatest room for improvement. At most recent assessment, injectable antibiotics, oxytocin and implantable contraceptives were the most widely available (Figure 2). Conversely, a number of reproductive and child health commodities had declined in availability including female condoms (-11 pp), emergency contraceptives (-2 pp), and amoxicillin (-12 pp). In nearly half of facilities, Misoprostol, Chlorhexidine, and neonatal resuscitation equipment were unavailable at the most recent facility assessment.

Stock-outs at national warehouses occurred more often over time (Table 2) and were most prevalent at the most recent assessment for magnesium sulfate, chlorhexidine, and zinc (see Online Supplementary Document Table B). Conversely, female condom, contraceptive implants, and injectable antibiotics for newborns had the fewest national stock-outs by 2017. Across countries, only a handful of commodities (7\%) were added into eLMIS to track distribution from central warehouses to service delivery points (Table 2 ). By 2017, just over half (57\%) of life-saving commodity were tracked in eLMIS across countries (Table 2), while comprehensive monitoring platforms exist in less than half of countries.

\section{HEALTH WORKER PERFORMANCE}

Over the observation period, health facilities with a recently trained staff member rose by eight percentage points $(P=.003)$ to $46 \%$ (Table 1$)$. In addition, availability of jobaids and/or checklists at health facilities increased to $66 \%$ (+13 pp). Moreover, to support workforce performance, $12 \%$ and $19 \%$ of life-saving commodities were added to national training curricula and job aids, respectively, across countries (Table 2). 
Table 1: Median percentage change over time for quantitative UNCoLSC indicators derived from health facility and population-based surveys - cumulative across 14 countries and commodities

\begin{tabular}{|c|c|c|c|c|c|c|c|}
\hline $\begin{array}{c}\text { UNCoLSC } \\
\text { RECOMMEND- } \\
\text { ATION }\end{array}$ & $\begin{array}{l}\text { Indicator and Definition to } \\
\text { meet minimum threshold }\end{array}$ & $\mathrm{n}$ & $\begin{array}{l}\text { Baseline } \\
\text { Median \% } \\
(95 \% \mathrm{Cl})\end{array}$ & $\begin{array}{l}\text { Endline } \\
\text { Median \% } \\
(95 \% \mathrm{Cl})\end{array}$ & $\begin{array}{l}\text { Change } \\
\text { Median }\end{array}$ & P-value & \\
\hline $\begin{array}{l}\text { Supply and } \\
\text { Awareness }\end{array}$ & $\begin{array}{l}\text { Percentage of facilities with } \\
\text { stock available: } \% \text { of health } \\
\text { facilities with no commodity } \\
\text { stock-out at time of } \\
\text { assessment (for facilities } \\
\text { authorized to provide the } \\
\text { commodity) }\end{array}$ & 109 & $\begin{array}{l}69.0(60.2 \\
-77.8)\end{array}$ & $\begin{array}{l}74.0(70.2 \\
-77.8)\end{array}$ & $\Delta 5.0$ & 0.001 & ** \\
\hline \multirow{2}{*}{$\begin{array}{l}\text { Performance } \\
\text { and } \\
\text { accountability }\end{array}$} & $\begin{array}{l}\text { Percentage of facilities with } \\
\text { recent training: } \% \text { of health } \\
\text { facilities with a health } \\
\text { worker trained in service } \\
\text { delivery within the past } 12 \\
\text { or } 24 \text { months }[1,2]\end{array}$ & 31 & $\begin{array}{c}38.0 \\
(28.7-47.3)\end{array}$ & $\begin{array}{c}46.0 \\
(30.5-61.5)\end{array}$ & $\Delta 8.0$ & 0.003 & ** \\
\hline & $\begin{array}{l}\text { Percentage of facility with } \\
\text { job aids or check lists: \% of } \\
\text { health facilities where } \\
\text { relevant job aids / check lists } \\
\text { exist at the time of } \\
\text { assessment [1] }\end{array}$ & 18 & $\begin{array}{c}53.3 \\
(39.7-66.9)\end{array}$ & $\begin{array}{c}66.1 \\
(56.6-75.5)\end{array}$ & $\Delta 12.8$ & 0.071 & \\
\hline $\begin{array}{l}\text { Demand \& } \\
\text { Utilization }\end{array}$ & $\begin{array}{l}\text { Population coverage rate: \% } \\
\text { of affected population with } \\
\text { specified medical condition } \\
\text { receiving treatment with } \\
\text { appropriate life-saving } \\
\text { commodity }\end{array}$ & 36 & $\begin{array}{l}9.5(5.4 \\
-24.4)\end{array}$ & $\begin{array}{l}21.6(13.4 \\
-29.7\end{array}$ & $\Delta 12.1$ & 0.111 & \\
\hline
\end{tabular}

P-value: ** P-value $<0.01 *$ P-value $<0.05$

Notes:[1] Reported by the four service delivery areas (reproductive, maternal, newborn or child).

[2] Recent training defined as during 12 or 24 months preceding assessment depending on data source. SARA and SPA is 24 months while all other sources, such as SDP, recent training defined as 'during 12 months preceding assessment'.

\section{REGULATORY EFFICIENCY AND QUALITY STRENGTHENING}

Regulatory efficiency indicators were the strongest performers over time (Table 2). For example, across countries, an additional $20 \%$ of the life-saving commodities were collectively added to national essential medicines lists in the preferred formulation, $11 \%$ of commodities were incorporated into national treatment guidelines, and another $12 \%$ of commodities were fully registered in-country (each $P<.005)$. Collectively, regulatory indicators also had the fewest outstanding gaps by 2017.

In this study, countries strengthened the sampling and quality testing of drugs (i.e. post-market surveillance) and nearly all countries procured drugs from good manufacturing practice (GMP) accredited manufacturers (Table 2). Unfortunately, the capacity of national control laboratories has declined over time and patient safety monitoring remains low.

\section{GENERATING DEMAND AND REACHING WOMEN AND CHILDREN}

In this study, modest gains were made in establishing national demand generation and behavior change plans for life-saving commodities that included domestic budget al- locations (Table 2). During the observation period, small improvements were seen for removing financial access barriers (i.e. user fees); however, gaps still exist in approximately half of service delivery areas across countries (Table 2). Where data were available, coverage rates (i.e. percent of affected population receiving appropriate treatment) increased two-fold over the observation period $(P=.111)$, but remains low for many commodities (Table 1), such as ORS (median 37\%), Zinc (27\%), and contraceptive implants (6\%) (Online Supplementary Document Figure F).

\section{OTHER HEALTH SYSTEM ENABLERS}

Over time, results-based financing programs were more prevalent and all 14 countries had $\mathrm{RMNCH}$ coordinating mechanisms by 2017 (Table 2). However, countries struggled to finalize national costed RMNCH plans with secured domestic budget allocation as well as develop commodity security strategies. 


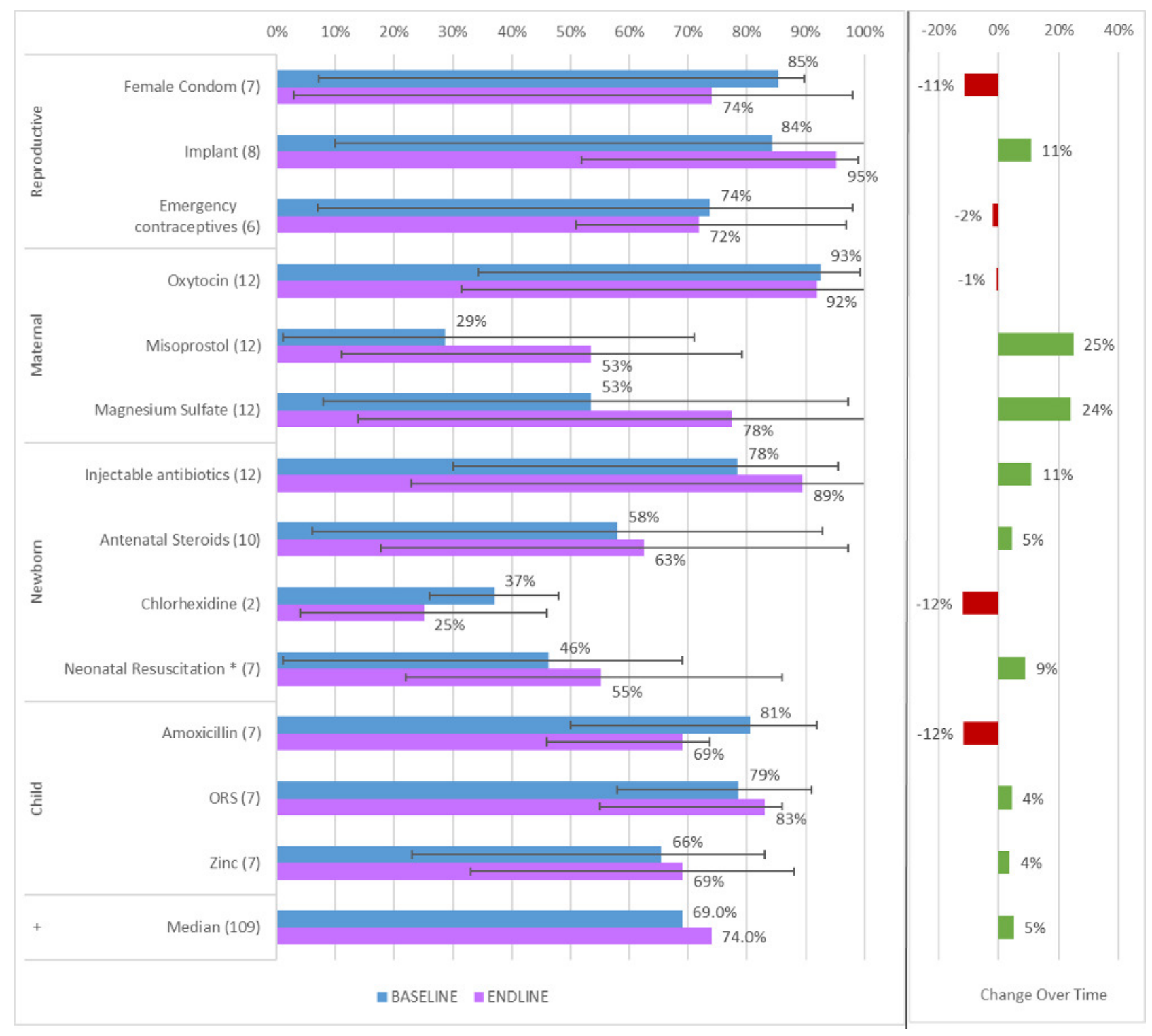

Figure 2: Median percentage of health facilities with stock availability at time of assessment by commodity across countries (number of countries with available survey result)

"In facility assessments, neonatal resuscitation is typically reported as availability of neonatal resuscitation "bag and mask".

|------| Minimum (left) and Maximum (right) values reported by a country for the commodity. 
Table 2: Proportion of categorical UNCoLSC indicators meeting minimum threshold over time -

cumulative across 14 countries and across commodities (where appropriate)

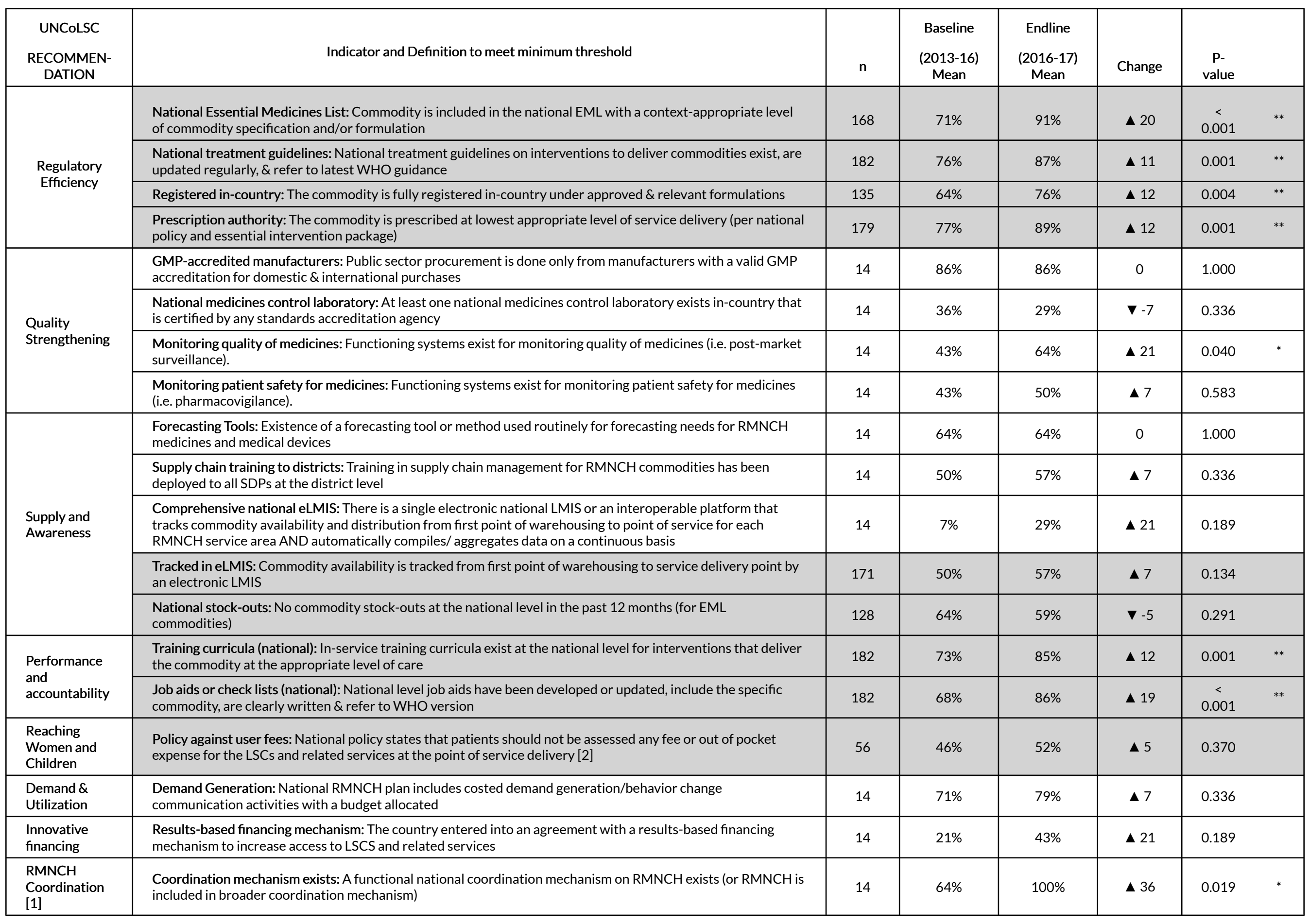




\begin{tabular}{|c|c|c|c|c|c|c|}
\hline $\begin{array}{l}\text { UNCOLSC } \\
\text { RECOMMEN- } \\
\text { DATION }\end{array}$ & Indicator and Definition to meet minimum threshold & $n$ & $\begin{array}{c}\text { Baseline } \\
\text { (2013-16) } \\
\text { Mean }\end{array}$ & $\begin{array}{c}\text { Endline } \\
\text { (2016-17) } \\
\text { Mean }\end{array}$ & Change & $\begin{array}{c}\text { P- } \\
\text { value }\end{array}$ \\
\hline & $\begin{array}{l}\text { RMNCH plan costed and budgeted: A national RMNCH plan exists that is costed with a budget allocated for } \\
\text { interventions for LSCs at national and sub-national levels }\end{array}$ & 14 & $57 \%$ & $50 \%$ & $\boldsymbol{\nabla}-7$ & 0.720 \\
\hline & $\begin{array}{l}\text { Commodity security strategy: National commodity security strategy for LSCs have been developed and } \\
\text { approved by the Ministry of Health }\end{array}$ & 14 & $43 \%$ & $36 \%$ & $\nabla-7$ & 0.336 \\
\hline & Total (average): & 1,551 & $65 \%$ & $76 \%$ & $11 \%$ & \\
\hline
\end{tabular}

Systems-related indicator (recorded once per country)

Commodity-specific indicator (recorded once per commodity per country)

P-value: ** P-value $<0.01 *$ P-value $<0.05$

Notes: [1] RMNCH Coordination is a performance indicator but not a UNCoLSC recommendation

[2] Policy against user fees is reported by the four service delivery areas (reproductive, maternal, newborn or child). 


\section{DISCUSSION}

This study assessed the ambitious UNCoLSC recommendations to improve availability and access to 13 life-saving commodities among countries in Africa and Asia with among the highest global burden of preventable maternal child deaths. Service readiness, including availability of commodities, improves the likelihood of receiving good quality services. ${ }^{7,16-18}$ Over the observation period, commodities were collectively more available; however, some commodities fared better than others (Figure 2). Commodities to reduce maternal deaths, treat newborn infection, and long acting methods for pregnancy prevention became more widely available. Scale-up of contraceptive implants have been a concerted focus of recent international and domestic efforts, ${ }^{19,20}$ while the low cost and long regulatory history of oxytocin and injectable antibiotics, such as gentamicin, facilitate efficient delivery through the supply chain. ${ }^{21-23}$ Conversely, access to misoprostol, chlorhexidine, antenatal corticosteroids and newborn resuscitation equipment still hovers around half of health facilities. Emerging science on the effective use of Chlorhexidine ${ }^{24}$ and antenatal corticosteroids ${ }^{15,25}$ produced operational reexamination, clouded guidance and limited scale-up. While the administration of misoprostol to prevent and treat postpartum hemorrhage is expanding to home-births, ${ }^{26}$ it can also be used to induce abortion, which can limit cultural adoption and the need for local stock availability.

Maintenance of national stock levels for essential commodities declined over the observation period and requires urgent attention. Increasing the use of centralized procurement through partners, such as family planning commodities, is cost-effective and efficient, but needs complementary in-country coordination. ${ }^{27,28}$ Often the discordance of national budget and cash flow cycles impedes the efficient bulk purchase of commodities by national governments. Innovative bridge funding mechanisms or working capital facilities (with prompt payback terms) to support local procurement through established systems could reduce stockouts and save money. ${ }^{29}$ Once procured, ensuring efficient, timely and equitable distribution of commodities within country relies on electronic logistics management information systems (eLMIS). In-country supply chains are often fragmented across multiple partners along with the corresponding eLMIS, which limits performance and timely corrective action. ${ }^{30,31}$ The Health Data Collaborative (HDC) has set out to support the harmonization and more efficient use of information systems. ${ }^{32}$ Expanding the domain of HDC or applying the same principles to complex issues such as supply chains and eLMIS is warranted to reduce fragmentation and improve efficient data use.

Inadequate workforce competences is an underlying operational barrier to effective healthcare delivery. ${ }^{14,33}$ To further strengthen the patient-provider interface, countries in this study improved national health workforce resources (e.g. training curricula and job-aids / checklist) as well as facility-based training. Since countries trained staff at just under half of health facilities within 12 or 24 months, the ability to reach all facilities could take approximately three to five years (assuming equitable distribution). This collective training capacity should inform introduction rates for new commodity guidelines and technology in the future. Prioritized investments and improved metrics on health workforce training and guidance (e.g. job-aids) portend enhanced quality of service delivery. A new opportunity for acceleration is the Network for Improving Quality of Care (QOC) for Maternal, Newborn and Child Health, ${ }^{34,35}$ which aims to establish local quality improvement teams to identify quality shortfalls and undertake quick cycles of problem-solving for facility-driven improvement and preparedness. Unfortunately, the utilization and quality of facilitylevel care is clouded by the lack of coverage data ${ }^{36-38}$ for administration of life-saving interventions at health facilities (e.g. oxytocin, injectable antibiotics). Moreover, while this study had access to the health management information systems, such as DHIS2, in most countries, the data available from these sources at time of assessment was deemed insufficient to generate a valid estimate of intervention coverage over time.

Delays in regulatory approval limit pharmaceutical companies interest in providing drugs to developing countries, which creates a market opportunity for an influx of counterfeit drugs. ${ }^{39,40}$ In this study, regulatory indicators exhibited significant improvement; however, they require regular review to ensure the latest treatment guidelines and formulations are adopted and product registration does not expire. With the rise of counterfeit drugs in circulation, ${ }^{41}$ countries need quality controls and monitoring of medicines to ensure the safety and effectiveness of drugs is intact when reaching women and children. Aside from postmarket surveillance, there was little to no improvement in quality strengthening conditions, which have been persistent intractable bottlenecks. ${ }^{39}$ Several interconnected regional efforts, such as the African Medicines Regulatory Harmonization (AMRH) Initiative, ${ }^{42}$ continue to strengthen fragmented regulatory environments and improve the availability of safe and effective commodities.

The collective improvements against the UNCoLSC recommendations mirrored the predominance of supply side investments prioritized by country teams and financed via the RMNCH Fund (see Online Supplementary Document Figure B). More than $80 \%$ of these expenditures were allocated towards two UNCoLSC recommendations: supply and awareness (e.g. commodity procurement, integrated LMIS, and supply chain management); and health worker performance and accountability (e.g. staffing, training, supervision, job-aids / checklists). These RMNCH acceleration plans were developed by government-led RMNCH coordinating mechanisms using a resource mapping across partners 43,44 ; therefore, expenditures against the RMNCH Fund provide a window into national priorities and funding gaps facing governments, UN agencies and development partners (see Online Supplementary Document Table G). An example is provided below (Box 1), which outlines the experience of the United Republic of Tanzania with the RMNCH Fund. In terms of sustainability, the RMNCH Fund provided short-term catalytic funding towards the UNCoLSC agenda. This short-term funding is small relative to potential domestic allocations; however, domestic budget allocations were often unpredictable and vacillated year-to-year across countries (Table 2). This type of shorter-term gap filling to support existing country-derived strategic plans should 
complement new longer-term funding sources, such as the Global Financing Facility, as they are actuated and put towards the same strategic vision. ${ }^{45,46}$

There were several limitations in this analysis that are important to draw attention to. First, gaps in data availability, such as maternal and newborn service delivery at health facilities, persist and constrained interpretation of community impacts. This study used the RMNCH Situation Analysis process, which is relatively easy and low-cost to conduct, but relies on existing data sources. ${ }^{44,45}$ The tool can be adapted for country context, such as sub-national use or expanded commodity and equipment list, but d.oes not establish new primary quantitative datasets for analysis. Second, the identification of operational bottlenecks relies on performance thresholds defined by a panel of experts; however, during enumeration, participant input and categorization by individual enumerators may be subjective and introduce bias. Third, countries assessed that met the requirements for this study (e.g. multiple data collection rounds of the RMNCH Situation Analysis) may not represent conditions experienced in other countries or regions. Fourth, this study did not analyze global-level UNCoLSC recommendations (e.g. product innovation and market shaping), which were assessed in a previous study, ${ }^{12}$ but could affect progress against related in-country bottlenecks. Next, this study utilized point estimates from facility- and population-based surveys to statistically analyze trends. The raw datasets had limited availability and their analysis was beyond the scope of this study, but may generate more decisive results and worthy of future research. Finally, the timeliness and consistency of available data sources may obfuscate recent changes. For example, this study utilized health facility assessments supported by various international institutions, including UNFPA (service delivery point survey), WHO (service availability and readiness assessment), and USAID (service provision assessment). While UNFPA has by far the most frequent data collection, the WHO and USAID tools are more comprehensive. Unfortunately, the tools are not entirely compatible among agencies (such as content and methodologies) and collection schedules are uncoordinated. The inter-agency HDC has undertaken an effort to harmonize these tools and data collection schedule among partners. ${ }^{32}$

\section{CONCLUSION}

Over a five-year period, significant improvements in commodity availability and health workforce training at the facility level were observed overall. Important commodity-related bottlenecks, such as coordination mechanisms, regulatory requirements, and national training curricula and job-aids, were near fully rectified. However, critical supply chain and medicine safety functions showed inconsistent improvement and remain an impediment to universal access. Leveraging the lessons learned from this unfinished UNCoLSC agenda can help in-country and global initiatives - such as the African Medicines Regulatory Harmonization, Global Financing Facility, Health Data Collaborative, and Quality of Care Network - address these remaining barriers to women and children receiving life-saving commodities and ultimately reaching universal health coverage.

\section{Box 1. Implementation Experience: United Republic of Tanzania}

The United Republic of Tanzania received two rounds of financing: US $\$ 4.0$ million in early 2014; and US\$11.9 million in 2015 from the RMNCH Fund. Planning of grant investments was led by the government and involved diverse stakeholders including multiple governmental agencies, UN organizations, and implementing partners.

All interventions selected for grant funding were consistent with the national 'Sharpened One Plan' 47 as well as the Big Results Now ${ }^{48}$ agendas. The initial grant supported the registration of 12 Life Saving Commodities (with the exception of Chlorohexidine); roll out of information systems (eLMIS and ILS gateway) to assist supply chain management and p rocurement of essential commodities; and nationwide Comprehensive Emergency Obstetric and Newborn Care (CEmONC) assessment of facilities. The second round of engagement with RMNCH Fund, broadened the activities to include upgrade of eight facilities to CEmONC, 67 ambulances procured and delivered to districts, and the establishment of two blood banks to help deliver comprehensive maternal care.

To initiate the grant process, a diverse, multisector coordinating platform was established with regular meetings and discussions among stakeholders. This improved planning, resource allocation, and partnership between the Government and the UN agencies. The grant terms of the RMNCH Fund were flexible and allowed the Tanzanian coordinating platform autonomy to select and adjust investments in RMNCH activities as needed - starting with a life-saving commodities focus and then broadening. This enabled strategic and adaptive selection of interventions to meet national and local needs. Lastly, the timing and adaptive use of funds helped lay the foundation for future investment mechanisms, such as the Global Financing Facility (GFF).

Acknowledgements: Special thanks to Desmond Koroma, Lazasoa

Raharimanjato, Kavitha Viswanathan and Amani Siyam. Funding: No funding was received for the writing of this manuscript. [Note: Financing for RMNCH Fund was provided by Governments of Norway (NORAD) and United Kingdom (DFID), but they had no role in the writing of the manuscript.]

Author contributions: BN, DS, NS, and PP drafted the man- 
uscript. All authors contributed to the design of the assessment, analysis of data, writing of the manuscript, and agree with the results and conclusions.

Competing interests: The authors completed the Unified Competing Interest form at www.icmje.org/coi disclosure.pdf (available upon request from the corresponding author), and declare no conflicts of interest.

\section{Correspondence to:}

Bennett Nemser, MBA, MPH

University of the Western Cape,

Cape Town, South Africa

bnemser@gmail.com or 3699067@myuwc.ac.za

This is an open-access article distributed under the terms of the Creative Commons Attribution 4.0 International License (CCBY-4.0). View this license's legal deed at http://creativecommons.org/licenses/by/4.0 and legal code at http://creativecommons.org/licenses/by/4.0/legalcode for more information. 


\section{REFERENCES}

1. UNICEF, World Health Organization, World Bank Group, UNPD. Levels \& Trends in Child Mortality: Report 2017. New York, USA; 2017.

2. World Health Organization, UNICEF, UNFPA, World Bank Group. Trends in Maternal Mortality: 1990 to 2015. Geneva, Switzerland; 2015. https://www.unice f.org/eapro/MMR_executive_summary_final_mid-res.p df.

3. Alkema L, Chou D, Hogan D, et al. Global, regional, and national levels and trends in maternal mortality between 1990 and 2015, with scenario-based projections to 2030: A systematic analysis by the. Lancet. 2016;387(10017):462-474. doi:10.1016/S014 0-6736(15)00838-7.National

4. Every Woman Every Child. The Global Strategy for Women's , Children's and Adolescents' Health: Final Draft.; 2015.

5. World Health Organization, UNICEF. Tracking Progress towards Universal Coverage for Reproductive, Newborn and Child Health: The 2017 Report. Washington, DC; 2017. http://countdown203 0.org/reports-and-publications/countdown-2017-rep ort.

6. Liu L, Oza S, Hogan D, et al. Global, regional, and national causes of under-5 mortality in 2000-15: An updated systematic analysis with implications for the Sustainable Development Goals. The Lancet. 2016;388(10063):3027-3035. doi:10.1016/s0140-673 $\underline{6(16) 31593-8}$

7. Winter R, Yourkavitch J, Wang W, Mallick L. Assessment of health facility capacity to provide newborn care in Bangladesh, Haiti, Malawi, Senegal, and Tanzania. J Glob Health. 2017;8(1). doi:10.7189/i ogh.07.020509

8. Carvajal-Aguirre L, Amouzou A, Mehra V, Ziqi M, Zaka N, Newby H. Gap between contact and content in maternal and newborn care: An analysis of data from 20 countries in sub-Saharan Africa. Journal of Global Health. 2017;7(2). doi:10.7189/jogh.07.020501

9. Boerma T, Requejo J, Victora CG, et al. Countdown to 2030: Tracking progress towards universal coverage for reproductive, maternal, newborn, and child health. The Lancet. 2018;391(10129):1538-1548. do i:10.1016/s0140-6736(18)30104-1

10. Akachi Y, Kruk ME. Quality of care: Measuring a neglected driver of improved health. Bull World Health Organ. 2017;95(6):465-472. doi:10.2471/blt.1 6.180190
11. UN Every Woman Every Child. UN Commission on Life-Saving Commodities for Women and Children: Commissioners' Report 2012. New York, USA; 2012. $\underline{\mathrm{h}}$ ttps://www.unicef.org/media/files/UN_Commission_R eport_September_2012_Final.pdf.

12. Pronyk PM, Nemser B, Maliqi B, et al. The UN Commission on Life Saving Commodities 3 years on: Global progress update and results of a multicountry assessment. The Lancet Global Health. 2016;4(4):e276-e286. doi:10.1016/s2214-109x(16)000 46-2

13. International Health Partnership. 13 International Health Partnership. A global "Compact" for achieving the Health Millennium Development Goals. 2007. htt p://webarchive.nationalarchives.gov.uk/+/http://ww w.dfid.gov.uk/news/files/ihp/compact.pdf.

14. Dickson KE, Simen-Kapeu A, Kinney MV, et al. Every Newborn: Health-systems bottlenecks and strategies to accelerate scale-up in countries. The Lancet. 2014;384(9941):438-454. doi:10.1016/s0140-6 736(14)60582-1

15. Bhutta ZA. Using life saving commodities to save lives globally. The Lancet Global Health. 2016;4(4):e221-e222. doi:10.1016/s2214-109x(16)000 $\underline{62-0}$

16. Carvajal-Aguirre L, Mehra V, Amouzou A, et al. Does health facility service environment matter for the receipt of essential newborn care? Linking health facility and household survey data in Malawi. Journal of Global Health. 2017;7(2). doi:10.7189/jogh.07.0205 $\underline{08}$

17. Kanyangarara M, Chou VB, Creanga AA, Walker N. Linking household and health facility surveys to assess obstetric service availability, readiness and coverage: Evidence from 17 low- and middle-income countries. Journal of Global Health. 2018;8(1). doi:1 0.7189/jogh.08.010603

18. Corsi DJ, Subramanian SV. Association between coverage of maternal and child health interventions, and under- 5 mortality: A repeated cross-sectional analysis of 35 sub-Saharan African countries. Global Health Action. 2014;7(1):24765. doi:10.3402/gha.v7.2 $\underline{4765}$

19. Duvall S, Thurston S, Weinberger M, Nuccio O, Fuchs-Montgomery N. Scaling up delivery of contraceptive implants in sub-Saharan Africa: Operational experiences of Marie Stopes International. Glob Health Sci Pract. 2014;2(1):72-92. doi:10.9745/ghsp-d-13-00116 
20. Jacobstein R. Liftoff: The blossoming of contraceptive implant use in Africa. Glob Health Sci Pract. 2018;6(1):17-39. doi:10.9745/ghsp-d-17-00396

21. Management Sciences for Health, World Health Organization (WHO). International Drug Price Indicator Guide 2014. Medford, MA, USA; 2014.

22. PATH, USAID. Gentamicin for Treatment of Neonatal Sepsis: A Landscape of Formulation, Packaging, and Delivery Alternatives. Seattle; 2015. $\underline{\mathrm{h}}$ ttps://path.azureedge.net/media/documents/DT_gent amicin_rpt.pdf.

\section{23 World Health Organization. WHO}

Recommendations for the Prevention and Treatment of Postpartum Haemorrhage. Geneva, Switzerland; 2012. http://www.who.int/reproductivehealth/publica tions/maternal_perinatal_health/9789241548502/en/.

24. Osrin D, Colbourn T. No reason to change WHO guidelines on cleansing the umbilical cord. The Lancet Global Health. 2016;4(11):e766-e768. doi:10.1 016/s2214-109x(16)30258-3

25. Althabe F, Belizán JM, McClure EM, et al. A population-based, multifaceted strategy to implement antenatal corticosteroid treatment versus standard care for the reduction of neonatal mortality due to preterm birth in low-income and middleincome countries: The ACT cluster-randomised trial. The Lancet. 2015;385(9968):629-639. doi:10.1016/s01 40-6736(14)61651-2

26. Ononge S, Campbell OMR, Kaharuza F, Lewis JJ, Fielding K, Mirembe F. Effectiveness and safety of misoprostol distributed to antenatal women to prevent postpartum haemorrhage after child-births: A stepped-wedge cluster-randomized trial. BMC Pregnancy Childbirth. 2015;15(1). doi:10.1186/s1288 4-015-0750-6

27. UNFPA. UNFPA Quality Assurance Framework for the Procurement of Reproductive Health Commodities. Copenhagen, Denmark https://www.un fpaprocurement.org/documents/10157/37547/2042 9+UNFPA+RFQ+OA+Framework_low_V11.pdf/2f06239 e-de34-4afa-91e0-cd86fb9aca00.

\section{Pan American Health Organization. Operating} Procedures of the PAHO Revolving Fund. Washington, D.C.; 2016. http://www.paho.org/hq/index.php?optio $\underline{\mathrm{n}}=$ com_content \&view $=$ article \&id $=736 \&$ Itemid $=223$ 4\&lang=en.

29. Financing for Development Corporation (F4D). Executive Summary: Evaluation of Country-Level Constraints in Accessing Financing for the Procurement of Nationally Funded MNCH Commodities. Washington, D.C.; 2015. http://ghpro.d exisonline.com/sites/default/files/AccelerationFundsE xecSumCH_508Doc.pdf.
30. Bergum B-I, Nielson P, Sæbø JI. Patchworks of Logistics Management Information Systems: Challenges or Solutions for Developing Countries? IFIP Adv Inf Commun Technol. 2017;504(May):V-VI.

31. PATH. The Case for Developing and Deploying an Open Source Electronic Logistics Management Information System. Seattle, WA, USA; 2012. http s://path.azureedge.net/media/documents/TS_dhs_ope n_source e lmis.pdf.

32. Celades E, Cocoman O, Kitamura M, Wall L. Health Data Collaborative: Progress Report 2016-18. Geneva, Switzerland; 2018. https://www.healthdataco llaborative.org/fileadmin/uploads/hdc/Documents/H DC_Progress_Report_Update_AW_071218 Web.pdf.

33. 33 Management Sciences for Health. Toward Building Resilient Pharmaceutical Systems: SIAPS Final Report. Arlington, VA; 2017. https://www.siapsp rogram.org.

34. World Health Organization. Quality, Equity, Dignity (QED): A Network for Improving Quality of Care for Maternal, Newborn and Child Health: Monitoring Framework. Geneva, Switzerland; 2017. ht tp://www.who.int/maternal_child_adolescent/topics/q uality-of-care/quality-of-care-brief-m-e.pdf?ua=1.

35. World Health Organization. Quality Equity Dignity: A Network to Improve Quality of Care for Mothers, Newborns and Children. Geneva, Switzerland

36. Carvajal-Aguirre L, Vaz LM, Singh K, et al. Measuring coverage of essential maternal and newborn care interventions: An unfinished agenda. Journal of Global Health. 2017;7(2). doi:10.7189/jog h.07.020101

37. Madaj B, Smith H, Mathai M, Roos N, Van Den Broek N. Developing global indicators for quality of maternal and newborn care: A feasibility assessment. Bull World Health Organ. 2017;95(6):445-452I. doi:1 $\underline{0.2471 / \text { blt.16.179531 }}$

38. Dettrick Z, Firth S, Jimenez Soto E. Do strategies to improve quality of maternal and child health care in lower and middle income countries lead to improved outcomes? A review of the evidence. Myer L, ed. PLoS ONE. 2013;8(12):e83070. doi:10.1371/jour nal.pone. 0083070

39. Ndomondo-Sigonda M, Miot J, Naidoo S, Dodoo A, Kaale E. Medicines Regulation in Africa: Current State and Opportunities. Pharm Med. 2017;31(6):383-397. doi:10.1007/s40290-017-0210-X 
40. Dansie LS, Odoch WD, Årdal C. Industrial perceptions of medicines regulatory harmonization in the East African Community. Riccaboni M, ed. PLoS ONE. 2019;14(6):e0218617. doi:10.1371/journal.pon e.0218617

41. Clark F. Rise in online pharmacies sees counterfeit drugs go global. The Lancet. 2015;386(10001):1327-1328. doi:10.1016/s0140-673 $\underline{6(15) 00394-3}$

42. Ndomondo-Sigonda M, Miot J, Naidoo S, Ambali A, Dodoo A, Mkandawire H. The African Medicines Regulatory Harmonization Initiative: Progress to Date. MRAJ. 2018;6(2). doi:10.18103/mra.v6i2.1668

43. Bijleveld P, Maliqi B, Pronyk P, et al. Country perspectives on integrated approaches to maternal and child health: The need for alignment and coordination. Bull World Health Organ. 2016;94(5):401-404. doi:10.2471/blt.15.168823

44. Nemser B. Data-informed decision-making for life-saving commodities investments in Malawi: A qualitative case study. Mal Med J. 2018;30(2):111. do i:10.4314/mmj.v30i2.11
45. Euro Health Group. Evaluation of RMNCH Trust Fund Activities - Volume I: Final Evaluation Report. Vol I. Soborg, Denmark; 2017. https://www.unicef.or $\mathrm{g} /$ evaldatabase/files/RMNCH_Trust Fund_evaluatio n_Final_Reprt_Volume_II.pdf.

46. Fernandes G, Sridhar D. World Bank and the Global Financing Facility. BMJ. August 2017:j3395. do i:10.1136/bmi.j3395

47. United Republic of Tanzania - Ministry of Health. Sharpened One Plan: The National Road Map Strategic Plan to Accelerate Reduction of Maternal, Newborn and Child Deaths in Tanzania 2008-2015. United Republic of Tanzania; 2014.

48. United Republic of Tanzania - President's Delivery Bureau. Big Results Now! 2013/2014 Annual Report: Tanzania Development Vison 2025. Dar es Salaam; 2014. 


\section{SUPPLEMENTARY MATERIALS}

\section{Online Supplementary Document}

Download: https://www.joghr.org/article/12745-progress-towards-the-un-commission-on-life-saving-commoditiesrecommendations-after-five-years-a-longitudinal-assessment/attachment/34262.docx 